Article

\title{
A Power System Optimal Dispatch Strategy Considering the Flow of Carbon Emissions and Large Consumers
}

\author{
Jun Yang ${ }^{1, *}$, Xin Feng ${ }^{1}$, Yufei Tang ${ }^{2}$, Jun Yan ${ }^{2}$, Haibo $\mathrm{He}^{2}$ and Chao Luo ${ }^{1}$ \\ 1 School of Electrical Engineering, Wuhan University, Wuhan 430072, China; \\ E-Mails: xfeng@whu.edu.cn (X.F.); luochao_2011@whu.edu.cn (C.L.) \\ 2 Department of Electrical, Computer, and Biomedical Engineering, University of Rhode Island, \\ Kingston, RI 02881, USA; E-Mails: ytang@ele.uri.edu (Y.T.); jun_yan@my.uri.edu (J.Y.); \\ he@ele.uri.edu (H.H.) \\ * Author to whom correspondence should be addressed; E-Mail: JYang@whu.edu.cn; \\ Tel.: +86-27-6877-6346; Fax: +86-27-6877-2047.
}

Academic Editor: Neville Watson

Received: 25 May 2015 / Accepted: 20 August 2015 / Published: 26 August 2015

\begin{abstract}
The carbon emissions trading market and direct power purchases by large consumers are two promising directions of power system development. To trace the carbon emission flow in the power grid, the theory of carbon emission flow is improved by allocating power loss to the load side. Based on the improved carbon emission flow theory, an optimal dispatch model is proposed to optimize the cost of both large consumers and the power grid, which will benefit from the carbon emissions trading market. Moreover, to better simulate reality, the direct purchase of power by large consumers is also considered in this paper. The OPF (optimal power flow) method is applied to solve the problem. To evaluate our proposed optimal dispatch strategy, an IEEE 30-bus system is used to test the performance. The effects of the price of carbon emissions and the price of electricity from normal generators and low-carbon generators with regards to the optimal dispatch are analyzed. The simulation results indicate that the proposed strategy can significantly reduce both the operation cost of the power grid and the power utilization cost of large consumers.
\end{abstract}

Keywords: carbon emissions trading market; large consumers; theory of carbon emission; OPF (optimal power flow) 


\section{Introduction}

In the face of climate change and energy crisis, low-carbon development was the best approach to ensure sustainable social development [1-7]. In communities, optimal dispatches had been studied to minimize carbon emissions [8-10]. However, establishing a carbon emissions trading market [11-14] was also important to develop a low-carbon economy. Literature [15] presented the practical significance of carbon emissions trading on China's development of a low-carbon economy, and literature [16] presented the implications of $\mathrm{CO}_{2}$ price for the power sector decarbonization in China. Literature [17] proposed a conceptual model of power consumer behavior considering the influence mechanism and factors of power consumption choice under a personal carbon trading market. The Ministry of Finance in China had drawn a roadmap for implementing a carbon tax and a carbon market as part of the 12th Five-Year Plan, with starting dates for the carbon tax and the carbon market in 2012 and 2015, respectively to reduce carbon emissions [18-20]. A carbon emissions trading market would no doubt be very meaningful and promising. Chinese government launched the energy-saving generation dispatch (ESGD) in 2007 with which the annual coal could be saved [21]. Literature [22] proposed a new ESGD mode with which the power resources allocation could be optimized in a longer time horizon. However, the generation dispatch in literature [21,22] was not a market-based arrangement. Literature [23] presented a multi-objective model for the combined heat and power dispatch problem, where the emissions reduction and the fuel cost could be optimized simultaneously. However, this multi-objective model did not consider carbon trading, which is also a critical part in the power dispatch market.

Currently, some large industrial consumers of electricity, such as aluminum smelters and steel mills, which consumed electric energy in excess of a certain amount, were permitted to directly purchase electricity from generation companies [24]. Direct power purchase for large consumers was an important measure for the reformation of the electricity industry [25,26]. The large electricity consumers were permitted to purchase electric energy directly, either from the generation companies via long-term contracts or from the spot energy market. The large electricity consumers had the right to freely select power providers to reduce production costs. As a result, this approach helped not only to break the monopoly of power network corporations but also to establish a competitive and open electricity market [27]. Literature [28] discussed the impact of direct power purchase for large consumers on the Chinese power market, and the financial cost of large consumers was also analyzed. Because of the massive electricity demand of large consumers, these consumers would have a great impact on the low-carbon operation of the power system. Literature [29] proposed an economic dispatch of generators based on Carbon Dioxide trading scheme, but the direct power consumer was not considered. Literature [30] proposed an algorithm to efficiently combine heat and power production planning under the emission trading scheme, however it focused on the planning rather than dispatch. Literature [31] proposed an economic-emission dispatch model highlighting generation cost as well as the pollutant emissions, but the benefit of the power grid was not considered.

Based on a carbon trading market, how to minimize the economic cost and the carbon emission cost of direct power purchased by large consumers must be studied in the power system dispatch.

To address this issue, the carbon emission flow in the power grid must first be analyzed. Carbon emissions were usually calculated by using official energy consumption statistics and using a 
conversion of primary energy consumption, but this method could not reveal the characteristics of carbon emission from the generation side. Literature [32] proposed a carbon flow tracing method, which could address carbon accounting at the regional level and carbon intensity assessment at the user level, but it could not clearly trace the source of carbon emissions at each load. Literature [33-36] introduced the concept of "carbon emission flow in networks" and proposed a method to calculate the carbon emission flow in networks. By approaching the carbon emissions from a spatial perspective, carbon production and consumption were integrated in the analysis of carbon emission flow, which had some unique advantages, such as integration with energy flows, reasonable allocation of carbon mitigation obligations and easy identification of carbon utilization efficiency for the entire network. However, the power grid loss was neglected to simplify the calculation of the carbon emission flow, thus its applications were limited in a real power system.

Considering the power loss by allocating grid loss to the load side, the theory of carbon emission flow [33-36] is improved in this paper. Taking carbon emissions trading into account, an optimal dispatch strategy of a power system is proposed to minimize the economic cost, the carbon emission cost of large power consumers, and the operation cost of the power grid companies. The effects of the carbon emission price, the electricity prices of normal generators, and low-carbon generators on the optimal dispatch model are studied. Analysis based on the optimal dispatch strategy in the benchmark system with different numbers of large consumers is performed.

The rest of the paper is organized as follows. Section 2 improves the carbon emission flow theory by considering the power loss. Section 3 proposes a carbon-emissions flow based optimal dispatch strategy, including large consumers under the carbon emissions trading market. In Section 4, simulations on an IEEE 30-bus system are performed to investigate the performance of the proposed optimal dispatch strategy. Finally, conclusions are drawn in Section 5.

\section{The Improvement of the Carbon Emission Flow Theory}

Based on the carbon emission flow theory proposed in [33-36], a unit-node carbon emission flow incidence matrix and unit-load carbon emission flow incidence matrix were defined and calculated to trace the carbon flow. However, because power loss is neglected, the carbon emission flow theory cannot be used in a real power system. To address this issue, the network loss of the power grid is considered to improve the carbon emission flow theory in this paper.

\subsection{Allocating Power Loss to the Load Side}

With the development of the carbon trading market, power consumers not only must pay for the power purchased from generators but also should submit the corresponding carbon quotas for the carbon emission caused by power production [17]. As demands lead to production, the load becomes the source of carbon emissions [34]. Actually, the carbon emissions caused by power loss are also induced by the demands of the loads. As a result, the allocation of the power loss to the load side under the carbon trading market is helpful, as it encourages the load side to participate in energy-savings actions and carbon emissions reductions.

According to literature [37], electricity can be traced by using gross flows. Therefore, $P_{i-j}^{(g)}$ is denoted as an unknown gross flow in line $i-j$, which would flow if no power was lost. 


$$
\left|P_{i-j}^{(g)}\right|=\frac{\left|P_{i-j}^{(g)}\right|}{P_{i}^{(\mathrm{g})}} P_{i}^{(\mathrm{g})} \cong \frac{\left|P_{i-j}^{(\mathrm{a})}\right|}{P_{i}^{(\mathrm{a})}} \sum_{k=1}^{n}\left(\left[A_{u}^{-1}\right]_{i k} P_{G k}\right), \quad j \in \alpha_{i}^{(d)}
$$

where $P_{i-j}^{(\mathrm{a})}$ is the actual flow from node $i$ in line $i-j, P_{i}^{(\mathrm{a})}$ is the actual total flow through node $i, P_{i}^{(\mathrm{g})}$ is the total power flow through node $i$ without considering power loss, $P_{G k}$ is the active power output at node $k$, and $\alpha_{i}^{(d)}$ is the set of nodes supplied directly from node $i . n$ is the node number of the power system. And $A_{\mathrm{u}}$ in Equation (1) is a $n \times n$ matrix. The element on row $i$ and column $j$ in $A$ u can be calculated as:

$$
\left[A_{u l i j}\right]_{i j}=\left\{\begin{array}{lc}
1 & i=j \\
-c_{j i}=-\left|P_{j-i}^{(\mathrm{a})}\right| / P_{j}^{(\mathrm{a})} & j \in \alpha_{i}^{(u)} \\
0 & \text { otherwise }
\end{array}\right.
$$

where $\alpha_{i}{ }^{(u)}$ is the set of nodes supplying directly to node $i$. The gross demand $P_{L i}{ }^{(\mathrm{g})}$ at node $i$ can be calculated as:

$$
P_{L i}^{(\mathrm{g})}=\frac{P_{L i}^{(\mathrm{g})}}{P_{i}^{(\mathrm{g})}} P_{i}^{(\mathrm{g})} \cong \frac{P_{L i}^{(\mathrm{a})}}{P_{i}^{(\mathrm{a})}} P_{i}^{(\mathrm{g})}=\frac{P_{L i}^{(\mathrm{a})}}{P_{i}^{(\mathrm{a})}} \sum_{k=1}^{n}\left(\left[A_{u}^{-1}\right]_{i k} P_{G k}\right)
$$

where $P_{L i}{ }^{(a)}$ is the actual demand at node $i$. In addition, $P_{L i}{ }^{(\mathrm{g})}$ includes two parts, which are the actual demand and the network loss that is allocated to the node $i$. After $P_{i-j}^{(g)}$ and $P_{L i}^{(\mathrm{g})}$ have been calculated, the system can be transformed into a lossless network.

\subsection{Calculation of the Carbon Emission Flow}

Some useful variables are defined in Table 1.

Table 1. Definition of the variables.

\begin{tabular}{ll}
\hline Variables & \multicolumn{1}{c}{ Definition } \\
\hline$R_{U-N}$ & unit-node carbon emission flow incidence matrix \\
$R_{U-L}$ & unit-load carbon emission flow incidence matrix \\
$E_{G}$ & unit carbon emission intensity vector \\
$P_{N}$ & node active power flux matrix \\
$P_{G}$ & power injection distribution matrix \\
$P_{B}$ & branch power flow distribution matrix \\
$P_{L}$ & load distribution matrix \\
$\zeta_{N}$ & $N$ dimensionality row vector; all the elements are 1 \\
\hline
\end{tabular}

The unit-node carbon emission flow incidence matrix $R_{U-N}$ and the unit-load carbon emission flow incidence matrix $R_{U-L}$ are given by $R_{U-N}=\operatorname{diag}\left(E_{G}\right)\left[P_{N}\left(P_{N}-P_{B}^{T}\right)^{-1} P_{G}^{T}\right]^{T} \quad$ and $R_{U-L}=R_{U-N} \operatorname{diag}\left(\zeta_{N} P_{L}\right) P_{N}^{-1}$, respectively [36].

According to $R_{U-L}$, the load can clearly trace its carbon emission flow footprint supplied from each generator, and its gross carbon emission rate can be obtained. Thus, in the carbon trading market, every power user can correspondingly submit its carbon quotas based on $R_{U-L}$. 
In addition, the load can trace its power supply source according to the unit-load carbon emission flow incidence matrix $R_{U-L}$. In this paper, $R_{U-L}$ is used to limit large consumers to obtain their most power supply from direct generators to satisfy their direct supplying contract.

\section{The Carbon Emission Flow Based Optimal Dispatch Strategy Considering Large Consumers}

Large consumers and optimal operation of the power grid are of primary concern because they are the important aspects of a power system in the low-carbon environment. Compared to obtaining power from power grid companies, large consumers would rather obtain power directly from generators to reduce cost. As a result, determining how to obtain reasonable power directly from generators is an important issue for large consumers. Meanwhile, from the power grid companies' perspective, determining how to reduce the operation cost is important too. Based on the optimal power flow (OPF) method [38], this paper proposes an optimal dispatch model based on the improved carbon emission flow theory. The OPF is a complex non-linear programming problem [39], in which the power system will operate in a steady state to achieve a predetermined optimal target by adjusting available control means. This is different from the conventional power flow calculation. Mathematically, the OPF can be described as follows.

$$
\left.\begin{array}{ll} 
& \min f(u, x) \\
\text { s.t. } & g(u, x)=0 \\
& h(u, x) \leq 0
\end{array}\right\}
$$

By choosing different objective functions and control variables combined with corresponding constraints, OPF can be used to solve certain problems with different purposes.

In this paper, the proposed optimal dispatch model is presented as follows.

\subsection{Objective Function}

To minimize the operation cost of power grid and the power utilization cost of large consumers, the objective function can be expressed as follows.

$$
\text { Min } F=\mathrm{w}_{1} \times f_{\text {ploss }}+\mathrm{w}_{2} \times f_{\text {cost }}
$$

where $f_{\text {ploss }}$ is the power system loss measuring the operation cost of power grid companies. $f_{\text {cost }}$ is the production cost that large power consumers must pay in a carbon emissions trading market. W1 and $\mathrm{w}_{2}$ are the respective weights. In this paper, the active power outputs of generators are chosen as the system control variables.

The power system loss can be formulated as follows:

$$
f_{\text {ploss }}=\left(\sum_{i=1}^{N_{G}} P_{G i}-\sum_{j=1}^{N_{L}} P_{L j}\right) \times E
$$

where $P_{L j}$ is the active power demand at load bus $j, N_{L}$ is the total number of load buses, $P_{G i}$ is the power output of the generator $i$, and $N_{G}$ is the number of generators. $E$ is the electricity price that the power grid sells the electricity to normal power users. 
In the carbon emission trading market, the power utilization cost of large power consumers includes the power supply cost as well as the carbon emission cost. Therefore, the $f_{\text {cost }}$ of a load $i$ is calculated as follows:

$$
f_{\text {cost }}=\sum_{j=1}^{N_{G}}\left(R_{U-L(i-j)} / E_{G j} \times C_{G j}\right)+\left(e_{c}-e_{c 0}\right) \times C_{P}
$$

where $R_{U-L(i-j)}$ is the carbon emission flow rate contribution from generator $j$ to load $i . E_{G j}$ is the carbon emission intensity of generator $j$, and $C_{G j}$ is the unit electricity price, including the wheeling price [40]. $e_{c}$ is the quantity of carbon emission, which can be obtained from $R_{U-L} \cdot e_{c 0}$ is the initial carbon quotas, and $C_{P}$ is the unit price of carbon emission.

In the carbon trading market, carbon dioxide can be traded. If the carbon emission $e_{c}$ caused by power users is greater than their initial carbon quotas $e_{c 0}$, they can purchase additional carbon quotas from other power users with available carbon emission quotas. On the contrary, if the carbon emission $e_{c}$ caused by the power users is less than their initial carbon quotas $e_{c}$, the redundant carbon quotas can be sold to other users who need extra carbon quotas.

According to [17], the initial carbon quota of a consumer is the average of carbon quotas for all of the consumers. $e_{c 0 i}$ is the initial carbon quotas of the consumer $i$, and $e_{c i}$ is the carbon emission of consumer $i$. Assuming that the number of the consumers is $n, e_{c 0 i}$ can be expressed as follows:

$$
e_{c 0 i}=\frac{\sum_{i=1}^{n} e_{c i}}{n}
$$

\subsection{Constraints}

The corresponding constraints in the proposed optimal dispatch model must be satisfied.

(1) The power balance constraints.

The active power constraint and the reactive power constraint are given by:

$$
\begin{aligned}
& P_{i}-V_{i} \sum_{j=1}^{N} V_{j}\left(G_{i j} \cos \delta_{i j}+B_{i j} \sin \delta_{i j}\right)=0 \\
& Q_{i}-V_{i} \sum_{j=1}^{N} V_{j}\left(G_{i j} \sin \delta_{i j}-B_{i j} \cos \delta_{i j}\right)=0
\end{aligned}
$$

where $P_{i}, Q_{i}, V_{i}$ denote the active power demand, reactive power demand, voltage bus at bus $i$, respectively. $\delta_{i j}, G_{i j}, B_{i j}$ denote the phase angle difference, conductance, and susceptance between bus $i$ and bus $j$, respectively. $N$ is the number of the buses.

(2) The constraints of power system safety

The respective upper and lower limits of the active power output and the reactive power output of the generators are as follows:

$$
\begin{array}{ll}
P_{G i \min } \leq P_{G i} \leq P_{G i \max } & i \in N_{G} \\
Q_{G i \min } \leq Q_{G i} \leq Q_{G i \max } & i \in N_{G}
\end{array}
$$


where $P_{G i}$ and $Q_{G i}$ denote the active power and reactive power output at generator $i$, respectively; $P_{\text {Gimin }}$ and $P_{\text {Gimax }}$ denote the maximum and minimum active power at generator $i$, respectively; $Q_{\text {Gimin }}$ and $Q_{\text {Gimax }}$ denote the maximum and minimum reactive power at generator $i$, respectively.

The available transfer capacity limit of the transmission lines is as follows:

$$
\left|S_{i-j}\right| \leq S_{i-j}^{\max } \quad i \in N_{B}
$$

where $S_{i-j}{ }^{\max }$ denotes the available transfer capacity in line $i-j$, and $N_{B}$ denotes the number of branches. $S_{i-j}$ is the transfer power flow in line $i-j$.

The upper and lower limits of node voltages are denoted as follows:

$$
V_{i \min } \leq V_{i} \leq V_{i \max } \quad i \in N
$$

where $V_{i \min }$ and $V_{i \max }$ denote the minimum and maximum voltage of the bus $i$, respectively.

(3) The constraint of large consumers

As the large consumer is mostly supplied by direct generation, its power source should be restrained as:

$$
\alpha_{i-j}>\gamma
$$

where $i$ is the load bus, $j$ is the direct generator bus supplying power to bus $i, \alpha_{i-j}$ is the rate of active power contribution from generator $j$ to load bus $i$, and $\gamma$ is the threshold of direct power supply rate.

The $\alpha_{i-j}$ can be expressed as follows:

$$
\alpha_{i-j}=\left(R_{U-L(i-j)} / E_{G j}\right) / \sum_{k=1}^{N_{G}}\left(R_{U-L(i-k)} / E_{G k}\right)
$$

where $R_{U-L(i-k)}$ is the carbon emission flow rate contribution from generator $k$ to load $i$ and $E_{G k}$ is the carbon emission intensity of generator $k$.

The OPF model is a non-convex problem [41] that can be solved by the heuristic and probabilistic search methods (genetic algorithms). The heuristic and probabilistic search methods [42] can overcome the limitations of non-convex and discrete control variables, and they have advantages such as simplicity, easier implementation, fewer parameters, and faster convergence. The Genetic Algorithm has some unique abilities including fast convergence speed, robustness, and capability of searching the global optimal solution [43]. Other probabilistic search based methods (e.g., Particle Swarm Algorithm, Simulated Annealing) were ever used to solve the optimization problem, but their convergence ability was not good for the OPF model in this paper. Therefore, the genetic algorithm is used in this paper to solve the model. The flowchart of genetic algorithm is shown in Figure 1. The algorithm is implemented in the Matlab (R2010b) (The MathWorks, Natick, MA, USA) platform.

\section{Case Studies}

To investigate the performance of the proposed optimal dispatch strategy, simulations, and analysis of an IEEE 30-bus system are performed. As shown in Figure 2, the IEEE 30-bus system has six generators. Assuming that G1, G2, and G6 are normal generators and that G3, G4, and G5 are low-carbon generators, such as gas-fired generating units, the carbon emission intensities of normal generators and low-carbon generators are 0.875 and $0.525 \mathrm{~kg} \mathrm{CO}_{2} / \mathrm{kWh}[34]$, respectively. 


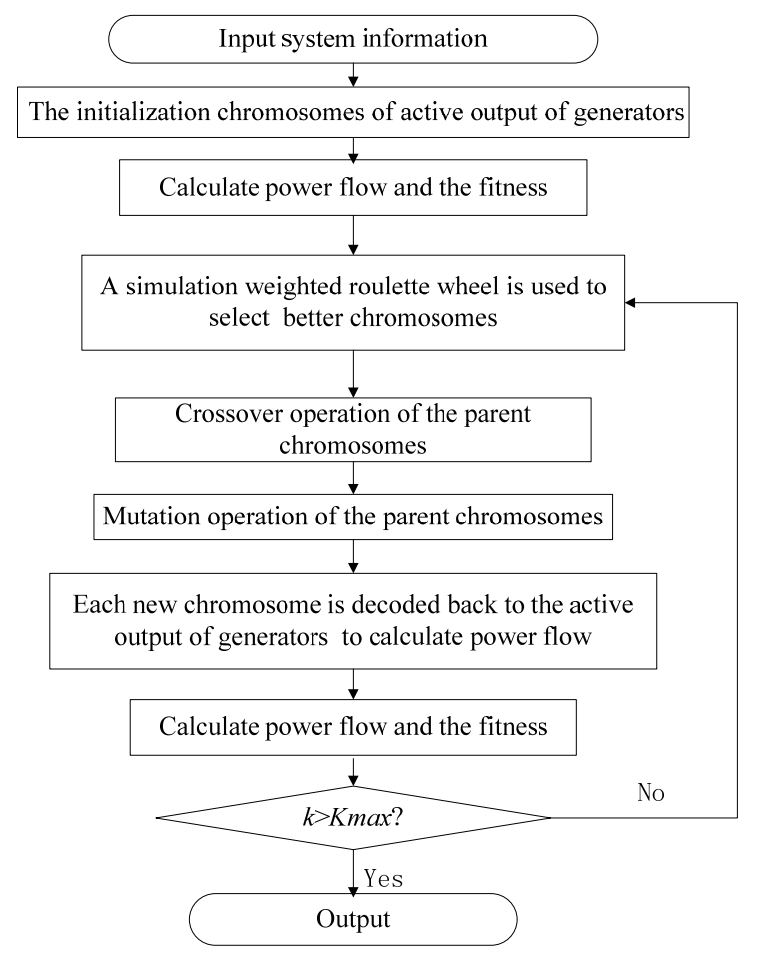

Figure 1. The flowchart of genetic algorithm.

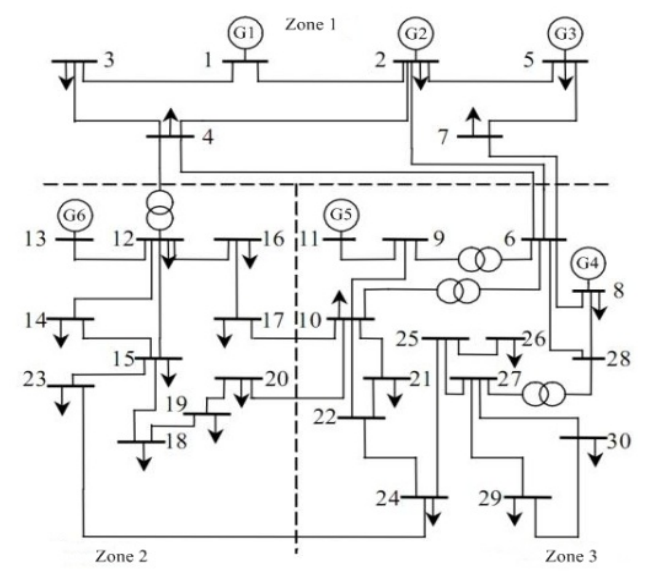

Figure 2. The IEEE 30-bus system.

For one operational mode of the power system, the results of the carbon emission flow distribution can be obtained according to the improved carbon emission flow theory. The $R_{U-L}$ of the operation mode is shown in Figure 3. As shown in Figure 3, the largest carbon emission flow rate bus is bus 5, which consists of G1, G2 and G3. Most of the carbon emission flow rate of bus 5 is caused by G3 because bus 5 is directly connected to G3. Bus 1 has no load, and the value of its carbon emission flow rate is zero. From these observations, we find that $R_{U-L}$ can help the load easily trace the carbon emission flow caused by each generator, and the gross carbon emission rate can be obtained from $R_{U-L}$ As a result, $R_{U-L}$ provides a reference for the carbon emission quotas for the load under the carbon trading market.

The emission carbon flow rates to each load calculated by the carbon emission flow theory in [33-36] and the improved carbon emission flow theory are shown in Table 2. 


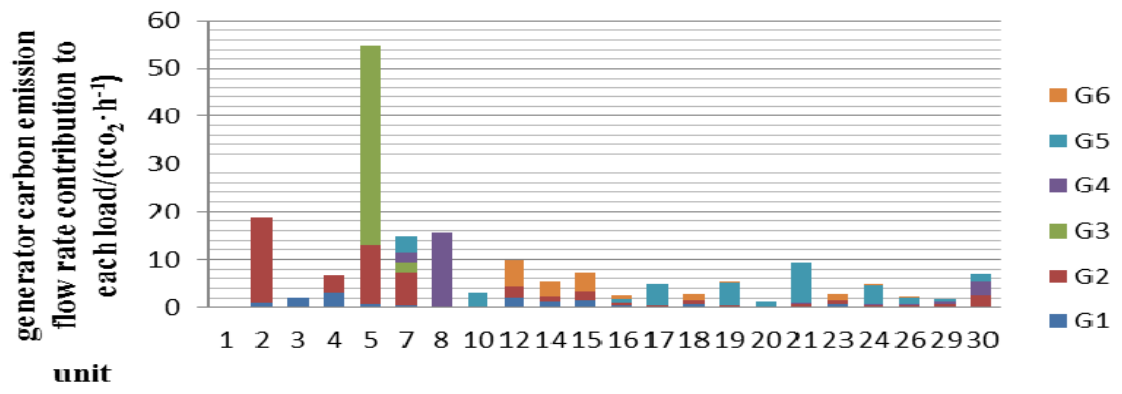

Figure 3. The contribution of each load to the carbon emission flow rate.

Table 2. The emission carbon flow rates calculated by the carbon emission flow theory and the improved carbon emission flow theory.

\begin{tabular}{|c|c|c|c|}
\hline Load & $\begin{array}{c}\text { Carbon Emission Flow } \\
\text { Theory } /\left(\mathrm{tCO}_{2} \cdot \mathbf{h}^{-1}\right) \\
\end{array}$ & $\begin{array}{c}\text { Improved Carbon Emission Flow } \\
\text { Theory } /\left(\mathrm{tCO}_{2} \cdot h^{-1}\right) \\
\end{array}$ & Error $/ \%$ \\
\hline 1 & 18.99 & 19.08 & 0.47 \\
\hline 2 & 2.10 & 2.13 & 1.41 \\
\hline 3 & 6.65 & 6.75 & 1.48 \\
\hline 4 & 53.12 & 53.24 & 0.23 \\
\hline 5 & 14.30 & 14.63 & 2.26 \\
\hline 6 & 3.13 & 3.15 & 0.63 \\
\hline 7 & 9.80 & 9.85 & 0.51 \\
\hline 8 & 5.43 & 5.50 & 1.27 \\
\hline 9 & 7.18 & 7.30 & 1.64 \\
\hline 10 & 3.06 & 3.10 & 1.29 \\
\hline 11 & 5.35 & 5.44 & 1.65 \\
\hline 12 & 2.80 & 2.86 & 2.10 \\
\hline 13 & 5.61 & 5.73 & 2.09 \\
\hline 14 & 1.19 & 1.21 & 1.65 \\
\hline 15 & 9.46 & 9.56 & 1.05 \\
\hline 16 & 2.80 & 2.87 & 2.44 \\
\hline 17 & 5.16 & 5.34 & 3.37 \\
\hline 18 & 1.91 & 2.05 & 6.83 \\
\hline 19 & 1.15 & 1.20 & 4.17 \\
\hline 20 & 5.08 & 5.36 & 5.22 \\
\hline Total & 164.27 & 166.34 & 1.24 \\
\hline
\end{tabular}

It can be observed from Table 2 that the emission carbon flow rate calculated by the improved carbon emission flow theory is greater than that by the carbon emission flow theory. This is because of the inclusion of power loss in the improved carbon emission flow theory.

To study the impact of the different number of large consumers on the proposed optimal model, two cases have been studied.

\subsection{Case A: One Large Consumer}

In the carbon trading market, the consumer not only must pay for the power purchased from generators but should also submit the corresponding carbon quotas for the carbon emission caused by 
power production. Compared with low-carbon generators, normal generators provide inexpensive power at the cost of higher carbon emissions, so the loads supplied by normal generators must submit more carbon emission quotas. In Case A, it is assumed that only one large consumer is located at bus 5 and that G2 and G3 are direct generators. Assuming that power prices of normal generators and low-carbon generators are 0.6 and $0.9 ¥ / \mathrm{kWh}$ [44], respectively, the initial $C_{p}$ is set as $150 ¥ / \mathrm{t}$ and $\gamma$ set as is 0.8 [45]. By using the Delphi method [46], about 10 experts from power grid companies are asked to determine the weights in this paper. And all of them think that the benefits of large consumers and power grid are of equal importance, so the weight $\mathrm{w}_{1}$ and $\mathrm{w}_{2}$ are considered as 0.5 .

\subsubsection{The Optimal Dispatch Results with One Large Consumer}

When the power system operates normally without optimizing the active power output of generators, this situation is defined as "without optimal dispatch". In normal operation, the power system operates stably, and the power flow distribution is controllable. No strategies are used in power systems during normal operation. And all power generation is under normal operation. If the proposed model is used to optimize the active power output of generators, the corresponding situation is defined as "with optimal dispatch".

The calculation of the genetic algorithm is repeated one-hundred times, and the average value of results is presented in Table 3 .

As presented in Table 3, the value of the objective function becomes smaller with the optimal dispatch scheme. In addition, the large consumer at bus 5 obtains more power from low-carbon generator G3 because of the carbon emission cost.

Table 3. The results with or without optimal dispatch.

\begin{tabular}{|c|c|c|c|c|c|c|c|c|c|c|c|}
\hline \multirow{2}{*}{$\begin{array}{l}\text { With or } \\
\text { Without } \\
\text { Optimal } \\
\text { Dispatch }\end{array}$} & \multicolumn{2}{|c|}{$\begin{array}{c}\text { Carbon Flow } \\
\text { Rate of Bus } \\
5 /\left(\mathrm{tCO}_{2} \cdot h^{-1}\right)\end{array}$} & \multicolumn{6}{|c|}{$\begin{array}{c}\text { Active Power Output of Each } \\
\text { Generator/MW }\end{array}$} & \multirow{2}{*}{$\begin{array}{c}\text { The } \\
\text { Objective } \\
\text { Function/ } ¥\end{array}$} & \multirow{2}{*}{$\begin{array}{c}\text { Power } \\
\text { System } \\
\text { Operation } \\
\text { Cost } ¥ \\
\end{array}$} & \multirow{2}{*}{$\begin{array}{c}\text { Large } \\
\text { Consumers } \\
\text { Cost } ¥ ¥\end{array}$} \\
\hline & G2 & G3 & G1 & G2 & G3 & G4 & G5 & G6 & & & \\
\hline $\begin{array}{c}\text { With } \\
\text { Optimal } \\
\text { Dispatch }\end{array}$ & 61.4 & 7.70 & 25.1 & 123.9 & 14.7 & 48.9 & 38.7 & 37.1 & 40,221 & 6303 & 74,139 \\
\hline $\begin{array}{l}\text { Without } \\
\text { Optimal } \\
\text { Dispatch }\end{array}$ & 62.8 & 5.54 & 5.94 & 103.2 & 5.54 & 33.41 & 13.4 & 56.3 & 40,700 & 6739 & 74,662 \\
\hline
\end{tabular}

\subsubsection{The Impact of the Carbon Emission Price $C_{p}$ on the Optimal Dispatch}

The price of carbon emission $C_{p}$ can affect the cost of the load sides; therefore, in this section, we will analyze the impact of $C_{p}$ on the power system's optimal dispatch. The effects of $C_{p}$ on the system's optimal dispatch are presented in Table 4. The range of $C_{p}$ is determined from [47].

When the carbon emission price increases from 80 to $170 ¥ / t$, it can be observed from Table 4 that the carbon flow rate supplied to the large consumer from G2 decreases, while that from G3 increases. The carbon flow rate from low-carbon generators in the same price range also increases, while the gross carbon flow rate decreases. The reason for this behavior is that the increase of $C_{p}$ leads the large 
consumer to obtain more power from low-carbon generators, such as G3, to reduce the carbon flow rate, although the price of power from low-carbon generators is higher than that from normal generators.

Table 4. Results under the condition of different carbon emission prices.

\begin{tabular}{|c|c|c|c|c|}
\hline \multirow[t]{2}{*}{$C_{p}(¥ / \mathbf{t})$} & \multicolumn{2}{|c|}{$\begin{array}{l}\text { Carbon Flow Rate } \\
\text { of Bus } 5 /\left(\mathrm{tCO}_{2} \cdot h^{-1}\right)\end{array}$} & \multirow{2}{*}{$\begin{array}{l}\text { Carbon Flow Rate of Bus } 5 \text { from } \\
\text { Low-Carbon Generators } /\left(\mathrm{tCO}_{2} \cdot \mathbf{h}^{-1}\right)\end{array}$} & \multirow{2}{*}{$\begin{array}{l}\text { Gross Carbon Flow Rate } \\
\text { of Bus } 5 /\left(\mathrm{tCO}_{2} \cdot \mathrm{h}^{-1}\right)\end{array}$} \\
\hline & G2 & G3 & & \\
\hline 80 & 69.5 & 2.72 & 3.32 & 82.95 \\
\hline 100 & 63.1 & 3.23 & 5.28 & 81.56 \\
\hline 150 & 61.4 & 7.70 & 10.62 & 77.49 \\
\hline 170 & 48.4 & 14.4 & 17.27 & 72.46 \\
\hline 180 & 62.6 & 8.47 & 11.60 & 76.69 \\
\hline 200 & 70.6 & 1.33 & 2.18 & 83.86 \\
\hline 300 & 63.5 & 6.52 & 9.17 & 78.54 \\
\hline 500 & 36.8 & 22.7 & 24.75 & 66.90 \\
\hline 700 & 10.9 & 43.0 & 43.02 & 53.89 \\
\hline 900 & 4.1 & 46.1 & 46.1 & 51.83 \\
\hline
\end{tabular}

When $C_{p}$ increases from 170 to $200 ¥ / \mathrm{t}$, the tendency of the carbon flow rate supplied to the large consumer from G2 and G3 is opposite to the situation above. The carbon flow rate from low-carbon generators decreases, while the gross carbon flow rate increases. The large consumer obtains more low-carbon electricity from G3 rather than normal electricity from G2, and the large consumer cost will increase because the reduced carbon emission cost is less than the increased cost for purchasing the low-carbon electricity.

When $C_{p}$ increases from 200 to $900 ¥ / \mathrm{t}$, the carbon flow rate supplied to the large consumer from G2 decreases, while that from G3 increases and the carbon flow rate from low-carbon generators increases. When $C_{p}$ is larger than $200 ¥ / t$, the large consumer prefers to purchase power electricity from low-carbon generators. In this situation, the cost for submitting carbon quotas is higher with higher carbon emission price, so purchasing low-carbon electricity rather than normal electricity to reduce carbon emissions is more beneficial.

The objective function, the large consumer cost, and the power system operation cost under conditions of different $C_{p}$ are shown in Figure 4. The data in Figure 4 indicates that the objective function and the large consumer cost have a similar variation tendency, while the power system operation cost yields a different curve.

When $C_{p}$ ranges from 80 to $170 ¥ / \mathrm{t}$ and from 200 to $900 ¥ / \mathrm{t}$, the large consumer’s cost increases, while the power system operation cost decreases. As shown in Table 4, G3 supplies more power to the large consumer so that it obtains less power from other generators. The power system operation cost would decrease because of the reduced power flow in the system, excluding the neighborhood of bus 5 . As the electricity price of low-carbon generators is higher, the cost to the large consumer would increase. Because the increased cost to the large consumer is greater than the reduced power system operation cost, the objective function will increase.

When $C_{p}$ ranges from 170 to $200 ¥ / \mathrm{t}$, the large consumer cost decreases, while the power system operation cost increases. This occurs because the large consumer obtains more electricity from normal 
generators rather than low-carbon generators. As the decreased cost to the large consumer is greater than the increased power system operation cost, the objective function will decrease.

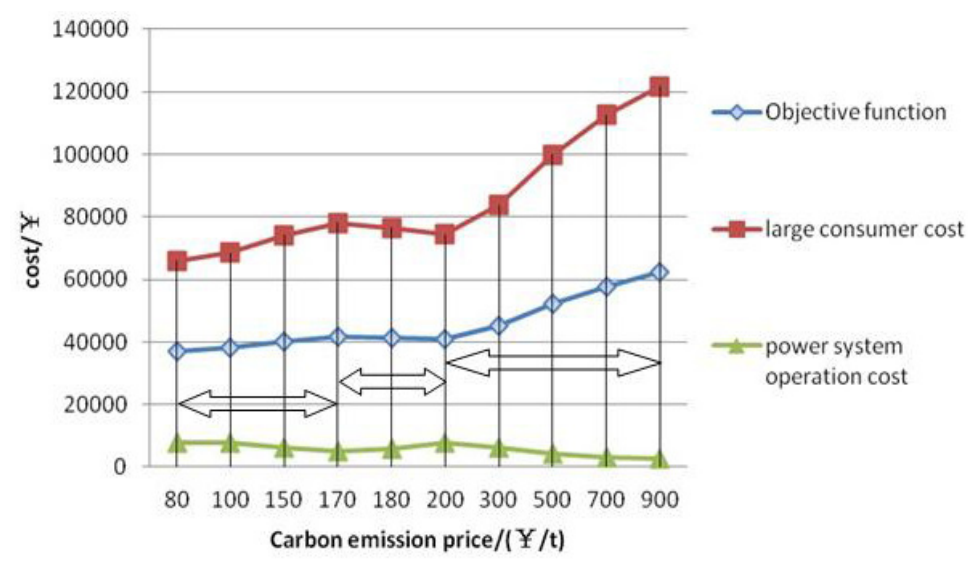

Figure 4. The variation tendency of the objective function, the large consumer cost and the power system operation cost.

In addition, each load has different carbon emission flow rates. The carbon emission flow rates of some loads may be larger than the initial carbon emission quotas, and others may be less than the initial quotas. The initial carbon emission quotas and carbon flow rates of some buses under the condition of different carbon emission prices are shown in Figure 5. Figure 5 shows that the carbon emission flow rates of bus 7 and bus 5 are always larger than initial carbon emission quotas, so they must purchase additional carbon emission quotas. The carbon emission flow rates of bus 4 are always smaller than the initial carbon emission quotas, so it can sell the remaining carbon emission quotas to other loads that need carbon emission quotas, e.g., bus 7 and bus 5. Because the power demand at bus 4 is small, the carbon emission fluctuation of bus 4 is small too.

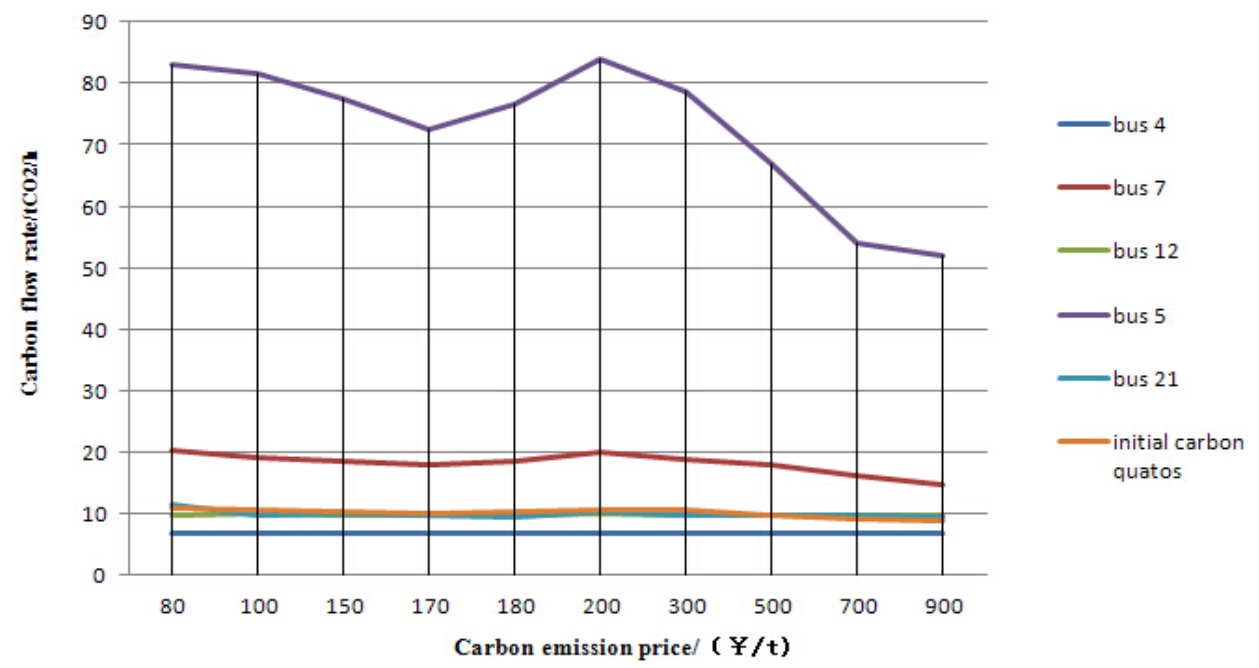

Figure 5. The carbon flow rate with one large consumer in the system.

4.1.3. The Impact of the Electricity Price of Normal Generators on the Optimal Dispatch

Table 5 shows the results under the condition of different electricity prices of normal generators. 
Table 5. Results under the condition of different electricity prices of normal generators.

\begin{tabular}{|c|c|c|c|c|c|c|c|}
\hline \multirow{3}{*}{$\begin{array}{c}\text { The Electricity Price } \\
\text { of Normal Generators } \\
¥ / \mathbf{k W h}\end{array}$} & \multicolumn{4}{|c|}{ Carbon Flow Rate of Bus 5/(tCO $\left.{ }_{2} \cdot h^{-1}\right)$} & \multirow{3}{*}{$\begin{array}{c}\text { The } \\
\text { Objective } \\
\text { Function/ } ¥\end{array}$} & \multirow{3}{*}{$\begin{array}{c}\text { Power System } \\
\text { Operation } \\
\text { Cost } / ¥\end{array}$} & \multirow{3}{*}{$\begin{array}{c}\text { Large } \\
\text { Consumer } \\
\text { Cost } ¥\end{array}$} \\
\hline & \multicolumn{2}{|c|}{$\begin{array}{c}\text { From Direct } \\
\text { Generators }\end{array}$} & \multirow{2}{*}{$\begin{array}{c}\text { From } \\
\text { Low-Carbon } \\
\text { Generators } \\
\end{array}$} & \multirow[t]{2}{*}{ Gross } & & & \\
\hline & G2 & G3 & & & & & \\
\hline 0.5 & 69.0 & 4.82 & 5.29 & 81.41 & 35,328 & 7954 & 63,132 \\
\hline 0.55 & 67.5 & 5.80 & 7.49 & 79.79 & 37,708 & 6949 & 68,682 \\
\hline 0.6 & 61.4 & 7.70 & 10.62 & 77.49 & 40,221 & 6303 & 74,139 \\
\hline 0.65 & 59.4 & 10.2 & 11.12 & 76.97 & 42,098 & 6240 & 77,955 \\
\hline 0.7 & 31.2 & 28.0 & 28.55 & 64.09 & 44,755 & 3981 & 85,528 \\
\hline
\end{tabular}

Table 5 indicates that when the electricity price of normal generators increases, the carbon flow rate supplied to the large consumer from G3 tends to increase, while that from G2 decreases. In addition, the carbon flow rate from all of the low-carbon generators increases with the increasing electricity price of normal generators because of the greater amount of power purchased from low-carbon generators. As a result, the carbon emission cost is reduced. Considering the higher electricity price of low-carbon generators, the cost to the large consumer will increase. When G3 supplies more power to the large consumer, which obtains less power from other generators, then the power system operation cost will decrease because of the reduced power flow in the system, excluding the neighborhood of bus 5 .

\subsubsection{The Impact of the Electricity Price of Low-Carbon Generators on the Optimal Dispatch}

Table 6 shows the results with different electricity prices of normal generators.

Table 6. Results under the condition of different electricity prices of low-carbon generators.

\begin{tabular}{|c|c|c|c|c|c|c|c|}
\hline \multirow{3}{*}{$\begin{array}{c}\text { The Electricity Price } \\
\text { of Low-Carbon } \\
\text { Generators } ¥ / \mathbf{k W h}\end{array}$} & \multicolumn{4}{|c|}{ Carbon Flow Rate of Bus 5/(tCO $\left.2 \cdot h^{-1}\right)$} & \multirow{3}{*}{$\begin{array}{c}\text { The Objective } \\
\text { Function/ } ¥\end{array}$} & \multirow{3}{*}{$\begin{array}{c}\text { Large } \\
\text { Consumer } \\
\text { Cost/ } ¥\end{array}$} & \multirow{3}{*}{$\begin{array}{c}\text { Power } \\
\text { System } \\
\text { Operation } \\
\text { Cost } ¥ ¥ \\
\end{array}$} \\
\hline & \multicolumn{2}{|c|}{$\begin{array}{c}\text { From Direct } \\
\text { Generators }\end{array}$} & \multirow{2}{*}{$\begin{array}{c}\text { From } \\
\text { Low-Carbon } \\
\text { Generators } \\
\end{array}$} & \multirow[t]{2}{*}{ Gross } & & & \\
\hline & G2 & G3 & & & & & \\
\hline 0.75 & 18.75 & 36.75 & 36.75 & 58.25 & 38,915 & 74,598 & 3232 \\
\hline 0.8 & 29.46 & 25.66 & 26.80 & 65.24 & 39,868 & 75,704 & 4033 \\
\hline 0.85 & 65.35 & 6.11 & 7.69 & 79.63 & 39,946 & 72,165 & 6728 \\
\hline 0.9 & 61.4 & 7.70 & 10.62 & 77.49 & 40,221 & 74,139 & 6303 \\
\hline 0.95 & 66.81 & 5.34 & 9.21 & 79.07 & 40,313 & 74,029 & 6597 \\
\hline 1.0 & 75.03 & 0.26 & 4.54 & 83.47 & 39,581 & 71,415 & 7746 \\
\hline
\end{tabular}

As shown in Table 6, when the electricity price of the low-carbon generators varies from 0.75 to $0.85 ¥ / \mathrm{kWh}$, the carbon flow rate supplied to the large consumer from G3 tends to decrease, while that from G2 increases. In this situation, the increasing carbon emission cost of purchasing power from normal generators is smaller than the increasing power cost from low-carbon generators, so the large consumer prefers to purchase power from the normal generators. When the electricity price of low-carbon generators increases from 0.85 to $0.9 ¥ / \mathrm{kWh}$, the carbon flow rate supplied to the large consumer from G2 tends to decrease, while that from G3 increases. In this situation, the increasing power cost from low-carbon generators is smaller than the increasing carbon emission cost of the 
purchasing power from normal generators. When the electricity price of low-carbon generators is higher than $0.9 ¥ / \mathrm{kWh}$, the increasing carbon emission cost of the purchasing power from normal generators becomes smaller than the increasing power cost from low-carbon generators. Thus, the large consumer obtains more power from the normal generators.

\subsection{Case B: Multiple Large Consumers}

In Case $\mathrm{B}$, we consider more than one large consumer in the power system, where $f_{\text {cost }}$ in the objective function is the sum of all of the consumers. Assuming two large consumers located at bus 5 and bus 21, respectively, the direct generators of bus 5 are G2 and G3, while the direct generators of bus 21 are $\mathrm{G} 2$ and G5. $C_{p}$ is set as $150 ¥ / \mathrm{t}$. The electricity prices of normal generators and low-carbon generators are set as 0.6 and $0.9 ¥ / \mathrm{kWh}$, respectively.

\subsubsection{The Results of the Optimal Dispatch Scheme}

The definitions of "without optimal dispatch" and "with optimal dispatch" are the same with that aforementioned in Table 3.

The results of the optimal dispatch with two large consumers are shown in Table 7.

Table 7. The optimal dispatch results of the system with two large consumers.

\begin{tabular}{|c|c|c|c|c|c|c|c|c|c|}
\hline \multirow[t]{2}{*}{$\begin{array}{l}\text { With or Without } \\
\text { Optimal Dispatch }\end{array}$} & \multicolumn{3}{|c|}{$\begin{array}{c}\text { Carbon Flow Rate of } \\
\text { Large Consumer at } \\
\left.\text { Bus 5/(tCO} 2 \cdot h^{-1}\right) \\
\end{array}$} & \multicolumn{3}{|c|}{$\begin{array}{c}\text { Carbon Flow Rate of } \\
\text { Large Consumer at } \\
\text { Bus } 21 /\left(\mathrm{tCO}_{2} \cdot h^{-1}\right) \\
\end{array}$} & \multirow[t]{2}{*}{$\begin{array}{c}\text { The } \\
\text { Objective } \\
\text { Function/ } ¥\end{array}$} & \multirow{2}{*}{$\begin{array}{c}\text { Power } \\
\text { System } \\
\text { Operation } \\
\text { Cost } ¥ \\
\end{array}$} & \multirow[t]{2}{*}{$\begin{array}{c}\text { Large } \\
\text { Consumer } \\
\text { Cost/ } ¥\end{array}$} \\
\hline & G2 & G3 & Gross & G2 & G5 & Gross & & & \\
\hline With optimal dispatch & 54.16 & 11.09 & 75.19 & 0.81 & 8.49 & 9.73 & 45,966 & 57,66 & 86,165 \\
\hline Without optimal dispatch & 57.29 & 8.83 & 77.20 & 2.36 & 6.64 & 10.77 & 47,664 & 6439 & 88,889 \\
\hline
\end{tabular}

As shown in Table 7, the value of the objective function becomes smaller with the optimal dispatch scheme, and large consumers at bus 5 and bus 21 obtain more power from low-carbon generators G3 and $\mathrm{G} 5$ because of the carbon emission cost.

4.2.2. The Impact of the Carbon Emission Price $C_{p}$ on the Optimal Dispatch of the System with Multiple Large Consumers

The results of the effects of $C_{p}$ on the system's optimal dispatch are presented in Table 8.

The Table 8 shows that when the carbon emission price $C_{p}$ increases from 80 to $170 ¥ / \mathrm{t}$ and from 200 to $900 ¥ / \mathrm{t}$, the large consumer’s cost will increase, while the power system operation cost will decrease. As the increased cost to the large consumer is greater than the reduced power system operation cost, the objective function will increase.

When the carbon emission price $C_{p}$ increases from 170 to $200 ¥ / t$, the large consumer cost will increase, and the power system operation cost will increase too. The result is different with the case of one large consumer. The reason is that the large consumer at bus 21 obtains more electricity from low-carbon generators. Meanwhile, the bus 21 and bus 5 have the same direct generator G2. As G2 is close to bus 5 in the system network, it supplies most of its power to bus 5; thus, bus 21 has to 
purchase power from the other direct generator G5 to satisfy the direct supply contract. So the large consumer's cost increases.

Table 8. Results under the conditions of different carbon emission prices.

\begin{tabular}{|c|c|c|c|c|c|c|c|c|c|}
\hline \multirow[t]{2}{*}{$C_{p} ¥ / \mathbf{t}$} & \multicolumn{3}{|c|}{$\begin{array}{c}\text { Carbon Flow Rate of Large } \\
\text { Consumer at Bus } 5 /\left(\mathrm{tCO}_{2} \cdot \mathrm{h}^{-1}\right)\end{array}$} & \multicolumn{3}{|c|}{$\begin{array}{c}\text { Carbon Flow Rate of Large } \\
\text { Consumer at Bus } 21 /\left(\mathrm{tCO}_{2} \cdot \mathbf{h}^{-1}\right)\end{array}$} & \multirow{2}{*}{$\begin{array}{c}\text { The } \\
\text { Objective } \\
\text { Function/ } ¥\end{array}$} & \multirow{2}{*}{$\begin{array}{c}\text { Power System } \\
\text { Operation } \\
\text { Cost } ¥ \mathbb{} \\
\end{array}$} & \multirow{2}{*}{$\begin{array}{c}\text { Large } \\
\text { Consumer } \\
\text { Cost } ¥ ¥ \\
\end{array}$} \\
\hline & G2 & G3 & Gross & G2 & G5 & Gross & & & \\
\hline 80 & 70.11 & 3.85 & 80.40 & 3.96 & 5.39 & 11.39 & 44,178 & 7978 & 80,379 \\
\hline 100 & 55.97 & 9.08 & 77.93 & 3.19 & 6.16 & 11.25 & 45,280 & 7306 & 83,255 \\
\hline 150 & 54.16 & 11.09 & 75.19 & 0.81 & 8.49 & 9.73 & 45,966 & 5766 & 86,165 \\
\hline 170 & 54.91 & 8.21 & 78.95 & 2.33 & 6.28 & 11.29 & 47,874 & 6959 & 88,789 \\
\hline 180 & 67.20 & 6.47 & 79.58 & 1.07 & 8.19 & 9.99 & 48,480 & 7017 & 89,942 \\
\hline 200 & 72.90 & 0.62 & 81.67 & 0.32 & 9.02 & 9.41 & 49,149 & 7098 & 91,200 \\
\hline 500 & 31.97 & 25.20 & 65.71 & 0.68 & 8.62 & 9.69 & 59,857 & 4107 & 115,610 \\
\hline 700 & 12.38 & 40.31 & 55.78 & 0.52 & 8.70 & 9.63 & 65,558 & 3224 & 127,890 \\
\hline 900 & 7.71 & 43.02 & 53.92 & 0.20 & 9.04 & 9.41 & 70,389 & 2804 & 139,750 \\
\hline
\end{tabular}

\subsubsection{The Impact of the Electricity Price of Normal Generators on the Optimal Dispatch}

The results of the impact of the electricity price of normal generators on the optimal dispatch are shown in Table 9. Table 9 shows that with an increasing electricity price of normal generators, the results are the same with the above case of one large consumer. When the electricity price of normal generators increases, the carbon flow rate supplied to the large consumer at bus 5 from G3 tends to increase, while that from G2 decreases. The carbon flow rate supplied to the large consumer at bus 21 from G5 tends to increase, while that from G2 decreases except when the electricity price of normal generators varies from 0.5 to $0.55 ¥ / \mathrm{kWh}$. As presented in Table 9 , most of the carbon flow rate of G2 is supplied to bus 5 when the electricity price of normal generators is at $0.5 ¥ / \mathrm{kWh}$. So the carbon flow rate supplied to bus 21 from G2 is very small and the large consumer at bus 21 needs to obtain more power from G5 to satisfy the direct supplying contract.

Table 9. Results under the condition of different electricity prices of the normal generators.

\begin{tabular}{|c|c|c|c|c|c|c|c|c|c|}
\hline \multirow{2}{*}{$\begin{array}{c}\text { Power Price } \\
\text { of Normal } \\
\text { Generators } \\
¥ / \mathbf{k W h}\end{array}$} & \multicolumn{3}{|c|}{$\begin{array}{c}\text { Carbon Flow Rate to } \\
\text { Large Consumer at } \\
\text { Bus } 5 /\left(\mathrm{tCO}_{2} \cdot \mathbf{h}^{-1}\right) \\
\end{array}$} & \multicolumn{3}{|c|}{$\begin{array}{c}\text { Carbon Flow Rate } \\
\text { Large Consumer at } \\
\text { Bus } 21 /\left(\mathrm{tCO}_{2} \cdot \mathbf{h}^{-1}\right)\end{array}$} & \multirow[t]{2}{*}{$\begin{array}{c}\text { The Objective } \\
\text { Function/ } ¥\end{array}$} & \multirow[t]{2}{*}{$\begin{array}{c}\text { Power System } \\
\text { Operation } \\
\text { Cost } ¥\end{array}$} & \multirow[t]{2}{*}{$\begin{array}{c}\text { Large } \\
\text { Consumer } \\
\text { Cost/ } ¥\end{array}$} \\
\hline & G2 & G3 & Gross & G2 & G5 & Gross & & & \\
\hline 0.5 & 65.58 & 6.72 & 80.28 & 2.64 & 6.66 & 11.07 & 42,672 & 7448 & 77,896 \\
\hline 0.55 & 54.32 & 10.11 & 75.67 & 5.19 & 4.43 & 12.27 & 45,787 & 6875 & 84,698 \\
\hline 0.6 & 54.16 & 11.09 & 75.19 & 0.81 & 8.49 & 9.73 & 45,966 & 5766 & 86,165 \\
\hline 0.65 & 48.47 & 16.47 & 71.42 & 0.68 & 8.71 & 9.63 & 50,431 & 4958 & 96,904 \\
\hline 0.7 & 42.09 & 21.91 & 67.07 & 0.59 & 8.84 & 9.52 & 52,324 & 4260 & 100,390 \\
\hline
\end{tabular}

With the increasing electricity price of normal generators, the cost to the large consumer will increase. As the increased cost of large consumer is greater than the reduced power system operation cost, the objective function will increase. When G3 supplies more power to the large consumers, which 
obtain less power from other generators, then the power system operation cost will decrease because of the reduced large scale power flow in the system, excluding the neighborhood of bus 5 .

\subsubsection{The Impact of the Electricity Price of Low-Carbon Generators on the Optimal Dispatch}

The results of the impact of the electricity price of low-carbon generators on the optimal dispatch are presented in Table 10.

As shown in Table 10, when the electricity price of the low-carbon generators varies from 0.8 to $0.85 ¥ / \mathrm{kWh}$, the carbon flow rate supplied to the large consumer at bus 5 from G3 tends to decrease, while that from G2 increases. The carbon flow rate supplied to the large consumer at bus 21 from G2 tends to increase, while that from G5 decreases. The increasing carbon emission cost of purchasing power from normal generators is smaller than the increasing power cost from low-carbon generators, so the large consumers prefer to purchase power from the normal generators. When the electricity price of low-carbon generators increases from 0.85 to $0.9 ¥ / \mathrm{kWh}$, the carbon flow rate supplied to the large consumer at bus 5 from G2 tends to decrease but, the flow rate from G3 increases. The carbon flow rate supplied to the large consumer at bus 21 from G2 tends to decrease, while that from G5 increases. In this situation, the increasing power cost from low-carbon generators is smaller than the increasing carbon emission cost of the purchasing power from normal generators. When the electricity price of low-carbon generators is greater than $0.9 ¥ / \mathrm{kWh}$, the increasing carbon emission cost of the purchasing power from normal generators becomes smaller than the increasing power cost from low-carbon generators. Thus, both large consumers at bus 5 and bus 21 obtain more power from the normal generators.

Table 10. Results under the condition of different electricity prices of low-carbon generators.

\begin{tabular}{|c|c|c|c|c|c|c|c|c|c|}
\hline \multirow{2}{*}{$\begin{array}{c}\text { Power Price of } \\
\text { Low-Carbon } \\
\text { Generators } \\
¥ / \mathbf{k W h} \\
\end{array}$} & \multicolumn{3}{|c|}{$\begin{array}{c}\text { Carbon Flow Rate to } \\
\text { Large Consumer at } \\
\text { Bus } 5 /\left(\mathrm{tCO}_{2} \cdot \mathbf{h}^{-1}\right) \\
\end{array}$} & \multicolumn{3}{|c|}{$\begin{array}{c}\text { Carbon Flow Rate } \\
\text { Large Consumer at } \\
\text { Bus } 21 /\left(\mathrm{tCO}_{2} \cdot \mathbf{h}^{-1}\right)\end{array}$} & \multirow[t]{2}{*}{$\begin{array}{c}\text { The Objective } \\
\text { Function/ } ¥\end{array}$} & \multirow{2}{*}{$\begin{array}{c}\text { Power } \\
\text { System } \\
\text { Operation } \\
\text { Cost } ¥ ¥\end{array}$} & \multirow[t]{2}{*}{$\begin{array}{c}\text { Large } \\
\text { Consumer } \\
\text { Cost } \$ ¥\end{array}$} \\
\hline & G2 & G3 & Gross & G2 & G5 & Gross & & & \\
\hline 0.8 & 49.53 & 14.37 & 73.23 & 0.85 & 8.48 & 9.76 & 46,174 & 5383 & 86,965 \\
\hline 0.85 & 56.01 & 10.72 & 75.90 & 1.16 & 8.34 & 9.88 & 47,108 & 5734 & 88,482 \\
\hline 0.9 & 54.16 & 11.09 & 75.19 & 0.81 & 8.49 & 9.73 & 45,966 & 5766 & 86,165 \\
\hline 0.95 & 55.76 & 8.78 & 76.42 & 0.84 & 8.31 & 9.83 & 48,714 & 6213 & 91,216 \\
\hline 1.0 & 69.99 & 2.29 & 79.42 & 2.48 & 6.66 & 10.36 & 49,388 & 7229 & 91,547 \\
\hline
\end{tabular}

In addition, the variation tendency of the carbon flow rates with two large consumers in the system is shown in Figure 6. The carbon flow rates of bus 7 and bus 5 are always greater than the initial carbon emission quotas, so they must purchase additional carbon emission quotas. The carbon emission of bus 4 is always smaller than the initial carbon emission quotas, so it can sell the remaining carbon emission quotas to other loads that need carbon emission quotas. 


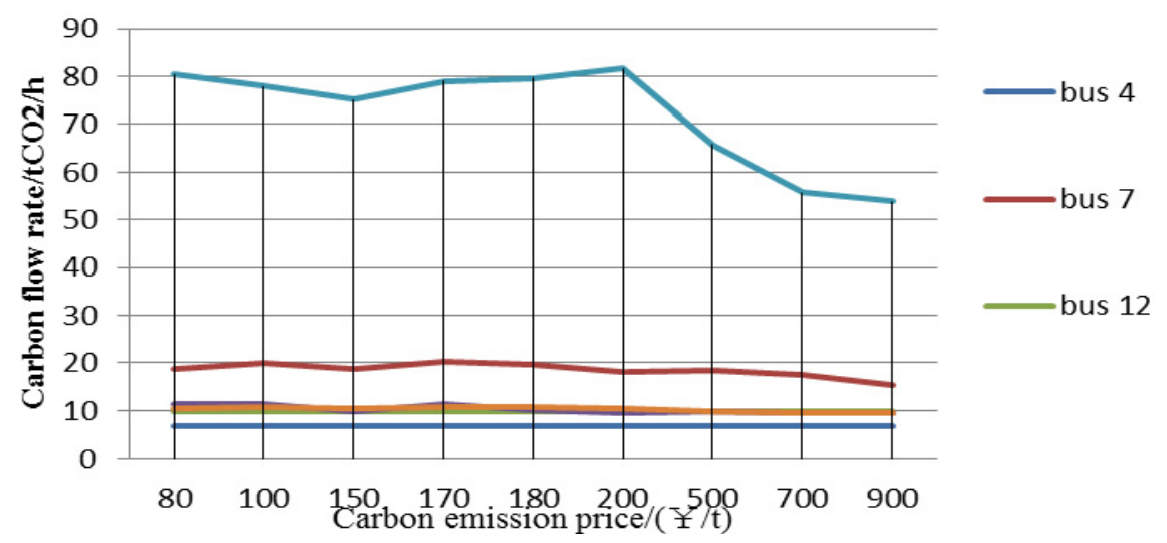

Figure 6. The variation tendency of the carbon flow rate with two large consumers in the system.

\section{Conclusions}

With the demand for energy dramatically increasing in the 21 st century, carbon emission reductions and low-carbon emission development are indispensable because of the global climate change caused by the release of carbon into the atmosphere. As a result, carbon emissions have become a serious concern for power systems. In this paper, to trace the carbon flow in a real power grid, the theory of carbon emission flow is improved by considering power losses in the power grid. The power losses are allocated to the load side, where the carbon emission caused by power losses is calculated. With the improved carbon emission flow theory, each load can trace its carbon flow rate, thus a reference can be obtained when submitting carbon quotas in the carbon trading market. Considering the cost of large consumers and the operational cost of a power grid under the carbon trading market, a power system dispatch strategy based on the improved theory of carbon emission flow is also proposed in this paper. As an important measure of electric industry reformation, large consumers and their direct power purchase ability are considered in the proposed dispatch model. To investigate the performance of the proposed optimal dispatch strategy, simulations with different numbers of large consumers are carried out based on an IEEE 30-bus system.

The simulation results indicate that the improved carbon emission flow theory can be used in the real power system by considering the power losses. And the proposed strategy can provide a reasonable dispatching mode to reduce the operational cost of the power grid as well as the power utilization cost of large consumers. Moreover, the simulation results demonstrate that the price of the carbon emission, the power price of normal generators, and the low-carbon generators have critical impacts on the dispatch results of the power system.

Based on the Matlab (R2010b) simulation platform, the genetic algorithm is used to solve the problem in a centralized manner. For large-scale power system, the calculation speed and solution accuracy may not satisfy the requirement. In future work, commercial software (e.g., Gurobi) as well as parallel computation methods may be needed to solve the problem.

\section{Acknowledgments}

The work is funded by the National Science Foundation of China $(51277135,50707021)$ and the Special Funds for the Projects of Basic Research and Operational Costs of the Central Universities. 


\section{Author Contributions}

Jun Yang led the development of the optimal dispatch strategy presented in this paper, as well as oversee the entire research developed in this paper. Xin Feng led the modeling and simulation based on the carbon emission flow theory. Jun Yan led the search algorithm development and comparative studies in this paper. Yufei Tang led the benchmark system development and case study in this paper. Haibo He led the genetic algorithm development as well as its integration with the proposed optimal dispatch strategy. Chao Luo led the simulation results analysis. All authors have contributed to the writing and editing of this paper.

\section{Conflicts of Interest}

The authors declare no conflict of interest.

\section{References}

1. Sir, S.N. The Stern review report on the economics of climate change. World Econ. 2006, 98, 1-10.

2. Kang, C.; Chen, Q.X.; Xia, Q. Prospects of low carbon electricity. Power Syst. Technol. 2009, 33, $1-7$.

3. Xin, J.-B.; Fan, R.-X.; Zheng, S.-J.; Zhao, W.-J.; Zhou, T.-R. Low-carbon benefit simulation and evaluation system for smart distribution grid and its application in Jiangxi Province. Power Syst. Prot. Control 2014, 42, 86-90. (In Chinese)

4. Zhu, Z.; Zhou, J.Y.; Han, Z.X.; Pan, Y. A low-carbon power dispatch model based on policy mechanisms corresponding to different stages. Power Syst. Technol. 2013, 37, 287-294. (In Chinese)

5. Albino, V.; Ardito, L.; Dangelico, R.M.; Petruzzelli, A.M. Understanding the development trends of low-carbon energy technologies: A patent analysis. Appl. Energy 2014, 13, 836-854.

6. Yu, S.; Wei, Y.M.; Guo, H.; Ding, L. Carbon emission coefficient measurement of the coal-to-power energy chain in China. Appl. Energy 2014, 114, 290-300.

7. Zhou, Y.; Li, Y.P.; Huang, G.H. Planning sustainable electric-power system with carbon emission abatement through CDM under uncertainty. Appl. Energy 2015, 140, 2350-2364.

8. Li, M.S.; Wu, Q.H.; Liao, H.L.; Tang, W.J.; Xue, Y.S. Optimal Power Flow with Environmental Constraints Using Paired Bacterial optimizer. In Proceedings of the IEEE Power and Energy Society General Meeting, San Diego, CA, USA, 24-29 July 2011; pp. 1-6.

9. Prasanna, T.S.; Somasundaram, P. Fuzzy mutated evolutionary programming based algorithm for combined economic and emission dispatch. In Proceedings of the IEEE TENCON 2008 IEEE Region 10 Conference, Hyderabad, India, 19-21 November 2008; pp. 1-5.

10. Faias, S.; de Sousa, J.; Castro, R. Environmental dispatch of the Portuguese power system for $\mathrm{CO}_{2}$ emissions reduction. In Proceedings of the IEEE 2011 8th International Conference on the European Energy Market (EEM), Zagreb, Croatia, 25-27 May 2011; pp. 389-394.

11. Zhang, F.W.; Guo, Y.; Chen, X.P. Research on China's Power Sector Carbon Emissions Trading Mechanism. Energy Procedia 2011, 12, 127-132.

12. Zhou, P.; Zhang, L.; Zhou, D.Q.; Xia, W.J. Modeling economic performance of interprovincial $\mathrm{CO}_{2}$ emission reduction quota trading in China. Appl. Energy 2013, 112, 1518-1528. 
13. Park, T.; Kim, C.; Kim, H. A real option-based model to valuate CDM projects under uncertain energy policies for emission trading. Appl. Energy 2014, 131, 288-296.

14. Tang, L.; Wu, J., Yu, L.; Bao, Q. Carbon emissions trading scheme exploration in China: A multi-agent-based model. Energy Policy 2015, 81, 152-169.

15. Qiang, F.; Tao, L. China's carbon emissions trading market with foreign experience on the background of low-carbon economy. Forum Sci. Technol. China 2010, 9, 106-111.

16. Li, Y.; Lukszo, Z.; Weijnen, M. The implications of $\mathrm{CO}_{2}$ price for China's power sector decarbonization. Appl. Energy 2015, 146, 53-64.

17. Fan, J. The Electricity Consumption Choice Based on the Model of Personal Carbon Trading Behavior. Ph.D. Thesis, University of Science and Technology of China, Hefei, China, 1 July 2012.

18. Chen, Q.; Kang, C.; Xia, Q.; Kirschen, D.S. Optimal flexible operation of a $\mathrm{CO}_{2}$ capture power plant in a combined energy and carbon emission market. IEEE Trans. Power Syst. 2012, 27, 1602-1609.

19. Wang, Q.; Su, B.; Sun, J.; Zhou, P.; Zhou, D. Measurement and decomposition of energy-saving and emissions reduction performance in Chinese cities. Appl. Energy 2015, 151, 85-92.

20. Fu, F.; Ma, L.; Li, Z.; Polenske, K.R. The implications of China's investment-driven economy on its energy consumption and carbon emissions. Energy Convers. Manag. 2014, 85, 573-580.

21. Gao, C.; Li, Y. Evolution of China's power dispatch principle and the new energy saving power dispatch policy. Energy Policy 2010, 38, 7346-7357.

22. Zhong, H.; Xia, Q.; Chen, Y.; Kang, C. Energy-saving generation dispatch toward a sustainable electric power industry in China. Energy Policy 2015, 83, 14-25.

23. Shi, B.; Yan, L.X.; Wu, W. Multi-objective optimization for combined heat and power economic dispatch with power transmission loss and emission reduction. Energy 2013, 56, 135-143.

24. Zheng, Y.; Li, G.; Zhou, M.; Liu, X. An integrated approach on allocating the congestion management cost under large consumers electricity direct purchase mode. In Proceedings of the third International Conference on Electric Utility Deregulation and Restructuring and Power Technologies, Nanjing, China, 6-9 April 2008; pp. 539-544.

25. Lei, Z.; Kun, G. Problems and countermeasure on direct purchase of electric energy by large users in our country. North China Electr. Power 2006, 9, 45-48.

26. Wang, Y.L.; Jian, S.; Li, Y.J. A model of admission of large consumers direct-purchasing based on Pareto optimal theory. Power Syst. Prot. Control 2010, 13, 2710-2714.

27. Qu, S.; Chen, H. The two-stage negotiation mechanism based on multi-agent using Q-learning in electricity bilateral contract. In Proceedings of the IEEE IPEC, Singapore, 27-29 October 2010; pp. 930-935.

28. Xia, Q.; Bai, Y.; Zhong, H.W.; Chen, Q.X. Initutional design and suggestions for promotion of direct electricity purchase by large consumers in China. Autom. Electr. Power Syst. 2013, 37, 1-7.

29. Tsai, M.T.; Yen, C.W. The influence of carbon dioxide trading scheme on economic dispatch of generators. Appl. Energy 2011, 88, 4811-4816.

30. Rong, A.; Figueira, J.R.; Lahdelma, R. An efficient algorithm for bi-objective combined heat and power production planning under the emission trading scheme. Energy Convers. Manag. 2014, 88, 525-534. 
31. Jubril, A.M.; Olaniyan, O.A.; Komolafe, O.A.; Ogunbona, P.O. Economic-emission dispatch problem: A semi-definite programming approach. Appl. Energy 2014, 134, 446-455.

32. Li, B.; Song, Y.; Hu, Z. Carbon flow tracing method for assessment of demand side carbon emissions obligation. IEEE Trans. Sustain. Energy 2013, 4, 1100-1107.

33. Kang, C.; Zhou, T.; Chen, Q.; Xu, Q.; Xia, Q.; Ji, Z. Carbon emission flow in networks. Sci. Rep. 2012, 2, 479.

34. Zhou, T.R.; Kang, C.Q.; Xu, Q.Y. Preliminary theoretical investigation on power system carbon emission flow. Autom. Electr. Power Syst. 2012, 36, 38-43.

35. Zhou, T.; Kang, C.; Xu, Q.; Chen, Q. Preliminary investigation on a method for carbon emission flow calculation of power system. Autom. Electr. Power Syst. 2012, 36, 44-49.

36. Zhou, T.; Kang, C.; Xu, Q.; Chen, Q.; Xin, J.; Wu, Y. Analysis on distribution characteristics and mechanisms of carbon emission flow in electric power network. Autom. Electr. Power Syst. 2012, 36, 39-44.

37. Bialek, J. Tracing the flow of electricity. IEE Proc. Génér. Transm. Distrib. 1996, 143, 313-320.

38. Momoh, J.A.; Koessler, R.J.; Bond, M.S.; Stott, B.; Sun, D.; Papalexopoulos, A.; Ristanovic, P. Challenges to optimal power flow. IEEE Trans. Power Syst. 1997, 12, 444-455.

39. Hayes, B.; Hernando-Gil, I.; Collin, A.; Harrison, G.; Djokic, S. Optimal power flow for maximizing network benefits from demand-side management. IEEE Trans. Power Syst. 2014, 29, 1739-1747.

40. Zhang, S.; Zhang, Y.; Chen, H. Key issues on direct power purchase by large consumers. East China Electr. Power 2009, 37, 523-528.

41. Yang, J.; He, L.; Fu, S. An improved PSO-based charging strategy of electric vehicles in electrical distribution grid. Appl. Energy 2014, 128, 82-92.

42. Lai, L.L.; Ma, J.T.; Yokoyama, R.; Zhao, M. Improved genetic algorithms for optimal power flow under both normal and contingent operation states. Int. J. of Electr. Power Energy Syst. 1997, 19, 287-292.

43. Xu, Y.F.; Xing, H.Q. The application and research analysis of genetic algorithm. Intell. Comput. Appl. 2010, 3, 113-115.

44. State Electricity Regulatory Commission People's Republic of China (SERC). Research Report of Electric Power Market and Power Price; China Electric Power Newspaper: Beijing, China, 2013; pp. 11-17.

45. Chen. Q.; Kang, C.; Xia, Q. Operation mechanism and peak-load shaving effects of carbon-capture power plant. Proc. CSEE 2010, 30, 22-28.

46. Lilja, K.K.; Laakso, K.; Palomki, J. Using the Delphi Method. In Proceedings of the IEEE Portland International Conference on Management of Engineering and Technology (PICMET), Portland, OR, USA, 31 July-4 August 2011; pp. 1-10.

47. Lu, S.; Lou, S.; Wu, Y.; Yin, X. Power system economic dispatch under low-carbon economy with carbon capture plants considered. IET Génér. Transm. Distrib. 2013, 7, 991-1001.

(C) 2015 by the authors; licensee MDPI, Basel, Switzerland. This article is an open access article distributed under the terms and conditions of the Creative Commons Attribution license (http://creativecommons.org/licenses/by/4.0/). 